\title{
Mechanical and Aging Properties of Polypropylene and Styrene-Butadiene- Styrene Composites under Outdoor and Indoor Conditions
}

\author{
M. Yimit, ${ }^{1}$ L. Ni, Y. Du, and R. Bkan
}

Key Laboratory of Oil and Gas Fine Chemicals, Ministry of Education and Xinjiang Uyghur Autonomous Region, College of Chemistry and Chemical Engineering, Xinjiang University, Urumqi, China

${ }^{1}$ mmtj10@sina.com (Mamatjan Yimit)

Polypropylene $(P P)$ and styrene-butadiene-styrene $(S B S)$ blends with different mass fractions were prepared in a molten state using a twin-screw extruder. The effect of SBS content on the microstructure and properties of PP/SBS was discussed by studying the morphology and mechanical properties of $P P / S B S$ outdoor aging samples, using differential scanning calorimeter, universal material testing machine, capillary rheometer, X-ray diffraction and X-ray photoelectron spectrometer. The results show that the best performance of unaged composites is 20\% PP/SBS composites without added compatibilizer. Low temperature test combined with dynamic thermal analysis found that the addition of SBS effectively improved the low temperature brittleness of PP. XRD tests indicate that $S B S$ can promote the formation of $\beta$ crystals in PP. Indoor and outdoor aging tests show that samples with $30 \%$ of SBS has excellent long-term anti-aging properties.

Keywords: polypropylene, styrene-butadiene-styrene, XPS, SEM, XRD, rheology.

Introduction. The rapid development of industrial technology has led to the synthesis of new polymers with different properties and structures to meet the growing demand of modern industry. Products made from polymeric composites, especially polypropylene (PP) is widely used in packaging, textile, household goods and automobile applications because it possesses a good balance of properties, such as easy processing capability, relatively high performance, great recyclability, low cost, excellent mechanical performance and durability [1-6]. However, these commercial-grade polymers contain ultraviolet (UV) stabilizers, antioxidants and light-transforming additives that makes them resistant to photo-oxidation, biodegradation, and chemical structure alteration and their application as a structural material is limited because of its relatively low strength at low temperature [7, 8]. However, because of the possibility of improvements in properties by the suitable selection of ingredients and ratios, polymer blends have gained considerable importance in recent decades. Nowadays, many successful applications resulting in polymer blends are considered in polymer engineering which was among the most important developments. The blending of polymers provides a smart and convenient method to produce new materials with versatility and tailor-made properties that vary with the miscibility or other properties of the components [6]. Rubber modification is a well-known approach for toughening PP, and considerable work has been carried out to overcome the problem, especially at low temperatures by incorporation of elastomers and rubbers such as ethylene-propylene copolymers, ethylene-propylene diene rubber, styrene/ethylene-butane/styrene, poly-isobutylene and styrene-butadiene block copolymer in the past twenty years $[6,9,10]$. In these rubbers, SBS mostly used for asphalt modification, thereby enhancing its impact toughness [11-20]. But SBS in the larger temperature difference has a good high temperature, low temperature resistance, and has good flexibility and toughness, for modified polypropylene temperature difference between the aging performance advantages. And as can be seen from literatures that most of the studies conducted by researchers on properties of polymer composites involve changing one of the independent factors at a time while maintaining the others at fixed level. Thus, this paper is to take the same method to explore the aging performance. 
Another PP copolymers, as well as all other synthetic plastics, are exposed to many environmental impacts during their service life, which may, due to their energetic nature, basically affect the physico-chemical characteristics of the material. Besides heat and atmospheric oxygen, it is especially the UV portion of incident solar radiation that initiates chemical reactions, leading to irreversible changes in the polymer backbone [21]. Therefore, the purpose of this work is to use SBS to overcome the shortcomings of low temperature toughness of polypropylene, as well as PP/SBS composite outdoor drying aging performance research and simple aging mechanism. Weathering was carried out at Xinjiang Turpan exposure site, representing the typical dry and hot climate.

1. Experimental.

1.1. Materials. PP (T30S: Homopolypropylene, drawing level and melt flow rate is $0.09 \mathrm{~g} / 10 \mathrm{~min}$ ) and SBS (YH792 (1401): butadiene/styrene 60/40 thermoplastic elastomer copolymer with linear structure and melt flow rate is $3.01-5 \mathrm{~g} / 10 \mathrm{~min}$ ) were purchased from China Petroleum Dushanzi Petrochemical Company and Baling Petrochemical.

1.2. Sample Preparation. The accurately weighed PP and SBS in a certain ratio (Table 1) were mixed in a high speed mixer for $15 \mathrm{~min}$, and then extruded through a twin-screw extruder (TE-20, Keya company China) at temperatures of 150, 190, 200, and $210^{\circ} \mathrm{C}$, before injection molded at temperatures of 200 and $210^{\circ} \mathrm{C}$ into shaped tensile splines by plastic injection molding machine (XL-400 VI: Ningbo China).

$\mathrm{T}$ a b 1 e 1

The Compound Proportion of PP and SBS

\begin{tabular}{|c|c|c|c|c|c|c||}
\hline Sample & PS-0 & PS-1 & PS-2 & PS-3 & PS-4 & PS-5 \\
\hline PP (wt.\%) & 100 & 90 & 80 & 70 & 60 & 50 \\
\hline SBS (wt.\%) & 0 & 10 & 20 & 30 & 40 & 50 \\
\hline
\end{tabular}

\subsection{Aging Test.}

1.3.1. PP/SBS Low Temperature Test. The low-temperature test was conducted in a low temperature test chamber. The impact spline was placed in a low temperature test chamber at temperatures of -20 and $-40^{\circ} \mathrm{C}$ for $240 \mathrm{~h}$, and samples were taken $24,48,96$, 144 , and $240 \mathrm{~h}$ to test the low temperature impact performance.

1.3.2. Indoor Aging Test. The indoor day/night accelerated weathering test simulates day and night temperature difference aging in outdoor dry heat environment. It is irradiated in daytime ultraviolet light for $12 \mathrm{~h}$ in a self-made ultraviolet light aging chamber, and then cooled to room temperature for $12 \mathrm{~h}$ after stopping irradiation in the evening. The temperature difference is $55^{\circ} \mathrm{C}$ and the period is 30 days, take samples every $3,6,9,15,20$, and 30 days.

1.3.3. Outdoor Aging Test. The PP samples were exposed in the world's second largest dry heat test station, Turpan natural environment research center of Xinjiang, China $\left(42^{\circ} 56^{\prime}\right.$ north, $89^{\circ} 12^{\prime}$ east, $61.5 \mathrm{~m}$ above the sea level). The PP standard samples were exposed to atmospheric conditions for about 4 months from May to September in the year of 2017, and the structure and mechanical properties of the samples were tested and analyzed. In addition, the meteorological data of the exposure testing period were provided by the Turpan Weather Center, and listed in Table 2.

1.4. Mechanical Properties. Tensile strength [22]: According to ISO 527:2012, the tensile specimens were tested at room temperature with a crosshead speed of $100 \mathrm{~mm} / \mathrm{min}$ using a computer-controlled universal testing machine (CMT6104, China). Tensile stress is calculated as follows:

$$
\sigma=\frac{P}{b d}
$$


Mechanical and Aging Properties of Polypropylene...

$\mathrm{T}$ a b 1 e 2

Weather Conditions during Outdoor Weathering Test Starting from May, 2017

\begin{tabular}{|c|c|c|c|c|c||}
\hline $\begin{array}{c}\text { Period } \\
\text { of weather } \\
\text { tests }\end{array}$ & $\begin{array}{c}\text { Average } \\
\text { sunshine } \\
\text { hours }(\mathrm{h})\end{array}$ & $\begin{array}{c}\text { Average intensity } \\
\text { of solar irradiation } \\
\left(\mathrm{W} \cdot \mathrm{h} / \mathrm{m}^{2}\right)\end{array}$ & $\begin{array}{c}\text { Average intensity } \\
\text { of UV irradiation } \\
\left(\mathrm{W} \cdot \mathrm{h} / \mathrm{m}^{2}\right)\end{array}$ & $\begin{array}{c}\text { Average } \\
\text { temperature } \\
\left({ }^{\circ} \mathrm{C}\right)\end{array}$ & $\begin{array}{c}\text { Average } \\
\text { humidity } \\
(\%)\end{array}$ \\
\hline May & 337.33 & 693.14 & 33.29 & 30.39 & 14.73 \\
\hline June & 302.46 & 633.56 & 32.02 & 34.86 & 17.47 \\
\hline July & 333.68 & 672.46 & 34.36 & 37.91 & 17.23 \\
\hline August & 304.43 & 671.12 & 32.25 & 33.56 & 20.93 \\
\hline September & 315.50 & 699.80 & 29.41 & 28.18 & 17.39 \\
\hline
\end{tabular}

where $\sigma$ is tensile strength in MPa, $P$ is maximum load, and $b$ and $d$ are the width and thickness of the sample in mm, respectively.

The elongation at break $(\varepsilon, \%)$ can be calculated as

$$
\varepsilon=\frac{L-L_{0}}{L_{0}} \cdot 100 \%
$$

where $L$ and $L_{0}$ are the length and initial length of the tensile break of the sample in mm, respectively.

Impact strength [22]: According to the standard ISO179:2010, an electronic impact testing machine (type XJJD-50, China) was used for impact test with a $7.5 \mathrm{~J}$ pendulum at room temperature. Impact strength is calculated as follows:

$$
a=\frac{W}{b h} \cdot 10^{3}
$$

where $a$ is the impact strength in $\mathrm{kJ} / \mathrm{m}^{2}, W$ is the corrected energy to break the sample in $\mathrm{J}$, and $b$ and $h$ are the sample width and thickness, respectively.

1.5. Characterization. Under the nitrogen atmosphere, samples were tested with a TA INSTRUMENTS model DMAQ800 thermal analyzer. The vibration type was bending, the vibration frequency was $1 \mathrm{~Hz}$, the scanning temperature range was $(-110)-50^{\circ} \mathrm{C}$, and the heating rate was $3{ }^{\circ} \mathrm{C} / \mathrm{min}$.

Scanning electron microscopic (SEM) images were obtained using the scanning electron microscopy (SEM, JSM-5600LV, JEOL, Ltd. Japan) to observe the surface morphology before and after aging of sample.

The Minilab test was performed using a micro mixing rheometer (MiniLab II, Haake, Germany) $6.0 \mathrm{~g}$ of PP and PP/SBS samples before and after aging treatment were added to the cylinder at a screw rotation speed of $30 \mathrm{rpm}$. The barrel temperature was set as $200^{\circ} \mathrm{C}$ and screw rod rotating was set as contrarotation. Collect 10 minutes of torque and time data.

The XRD curves of the samples were obtained using the X-ray diffraction analysis (XRD, D8 advance Bruker, Germany) $\mathrm{Cu}-\mathrm{K} \alpha$ radiation with $\mathrm{p}-\mathrm{Ni}$ filter $(U=40 \mathrm{kV}$, $A=40 \mathrm{~mA}$ ) in the $2 \theta$ range of 10 to 60 at a scan rate of $6 \mathrm{~min}$.

XPS (ESCALAB 250Xi, Thermo Fisher, USA) was used to investigate the surface composition of the before and after aging of PP and PP/SBS complex samples. X-ray photoelectron spectra were recorded on a Thermo spectrometer with a monochromatized Al K Alpha X-ray source (1486.6 eV photons). The details of the technique were given elsewhere. 


\section{Results and Discussion.}

2.1. The Performance of Low-Temperature Impact. Figure 1 shows the impact strength of PP/SBS blend samples. It can be seen from Fig. 1a that, with the increase of SBS content, the impact strength of the blended specimen increased at first and then decreased. The maximum value of PS-2 reached $37.57 \mathrm{MPa}$, which was $11.98 \%$ higher than that of pure PS-0 specimen; Fig. 1b and 1c are the impact strength of blend samples frozen at low temperature. With the extension of freezing time, the impact strength of blends tends to decrease, but the overall change is not significant, and it is better than the impact strength of pure PP samples. The PS-3 blend has the best low-temperature toughness. Moreover, no matter whether it is at a low temperature of -20 or $-40^{\circ} \mathrm{C}$, it's low temperature impact strength is higher than that of PS-0, indicating the achievement of modifying the low temperature brittleness of PP materials. This is because SBS has two $T_{g}$, $T_{g 1}=-80^{\circ} \mathrm{C}, T_{g 2}=90^{\circ} \mathrm{C}$, and PP's $T_{g}$ is about $-10^{\circ} \mathrm{C}$. Therefore, at low temperatures of -20 and $-40^{\circ} \mathrm{C}$, the segments of pure PP samples have been completely frozen, while the SBS segment in the blend sample still has some flexibility, and is still free to move, so the impact strength of the blend is higher than that of the pure PP sample.

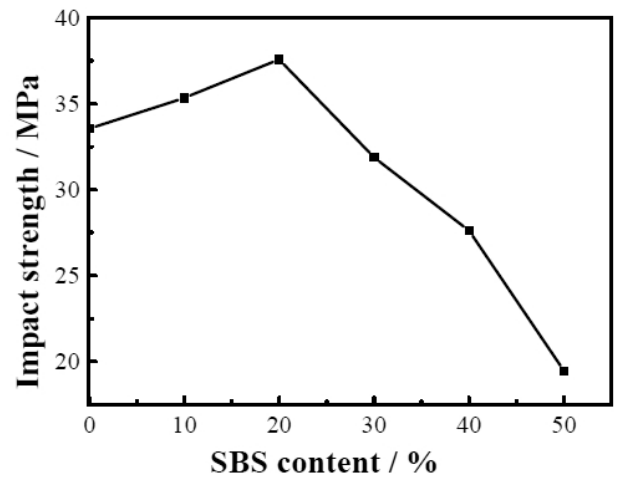

a

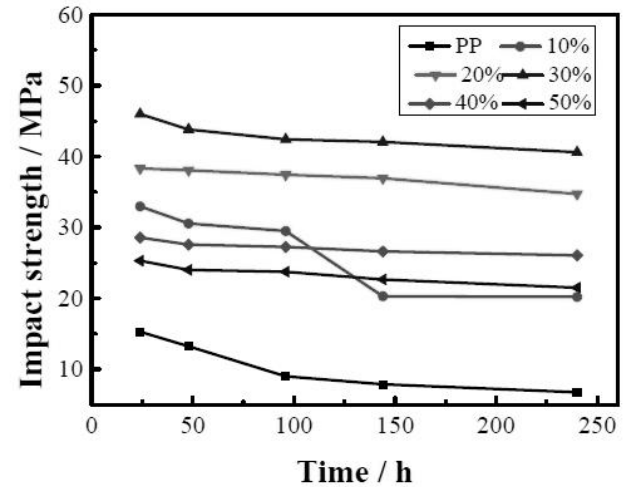

b

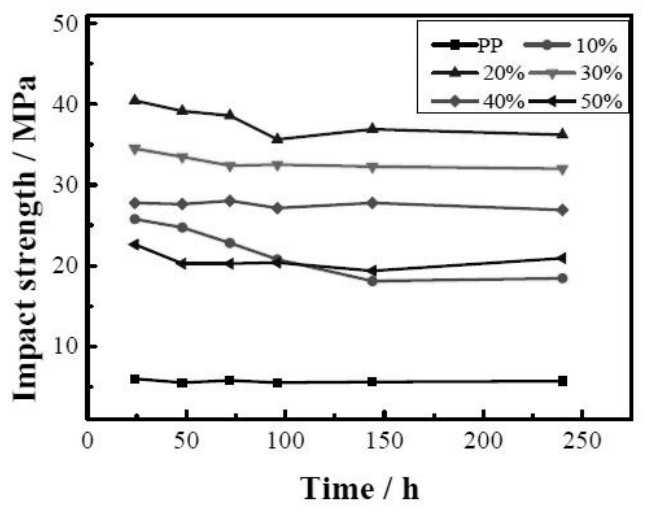

c

Fig. 1. Low-temperature impact strength of PP/SBS: (a) impact properties of PP/SBS specimens at room temperature; (b) $\mathrm{PP} / \mathrm{SBS}$ impact properties at different times at $-20^{\circ} \mathrm{C}$; (c) $\mathrm{PP} / \mathrm{SBS}$ impact properties at different times at $-40^{\circ} \mathrm{C}$.

2.2. Effects of SBS on the PP Dynamic Mechanical Behavior. Figure 2a and $2 b$ presents the loss modulus-temperature and loss factor-temperature plots of the PP/SBS blend system. As can be seen from Fig 2a, the PP/SBS blend system has two $T_{g}$ peaks, 
which is caused by the poor compatibility of PP and SBS. With the increase of SBS content, the $T_{g}$ peak of PP is almost not shifted. The $T_{g}$ peak of SBS is broadened because the higher the SBS content, the more segments that can move freely at low temperatures, the higher the impact strength at low temperature, and the better the low temperature toughness, which is also proved in the low temperature test. As can be seen from Fig $2 \mathrm{~b}$, PP has a significant room temperature peak $\tan \delta_{1}\left(T_{g_{1}}\right)$, which is due to the relaxation of the partially incompletely crystallized portion of the PP after the PP is rapidly reduced in temperature after injection molding. Compared with the pure PP sample, the $T_{g 1}$ of the PP/SBS blend slightly shifted, and the $\tan \delta_{1}$ peak intensity did not change significantly. The addition of the elastomer SBS showed a peak of $\tan \delta_{2}$ at low temperature, and with the increase of SBS content, The low-temperature internal friction peak $\tan \delta_{2}$ peak is enhanced and broadened because the addition of SBS and the entanglement of the flexible molecular chain increase the internal friction of the blend system, making the $\tan \delta_{2}$ peak enhanced while enhancing relaxation effect of the partially incomplete crystalline fraction in the PP.

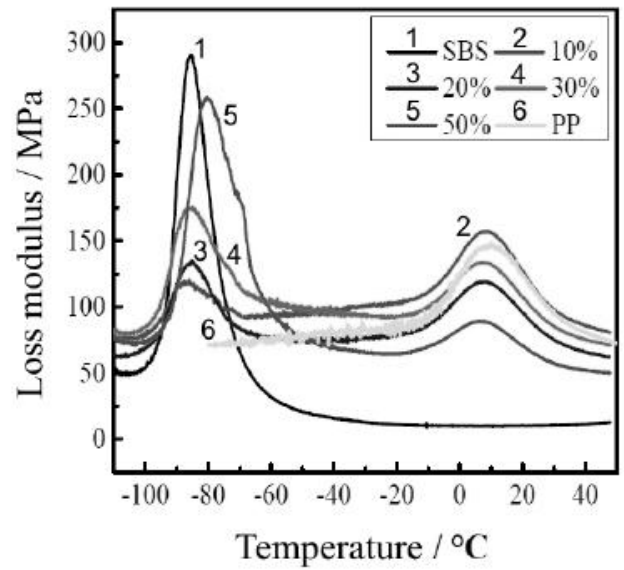

a

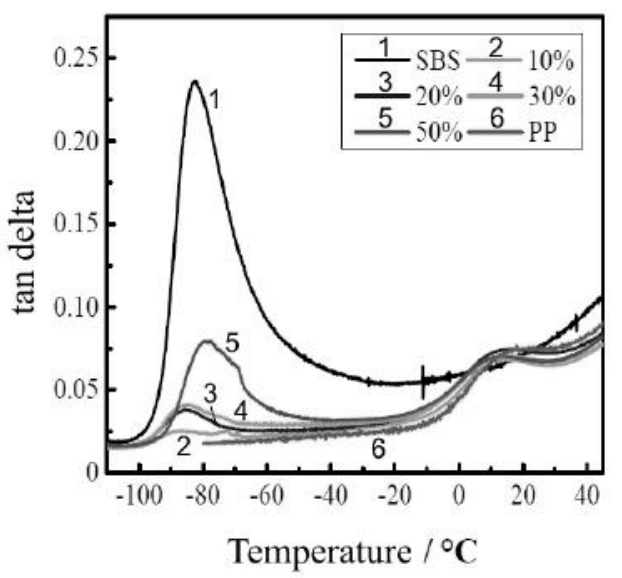

b

Fig. 2. Dynamic thermal analysis of PP/SBS: (a) loss modulus of PP/SBS blend system-temperature; (b) loss factor-temperature.

\subsection{Analysis of the Morphology of the Outer Layer of PP/SBS after Aging Outdoor.} Figure 3 presents the scanning electron micrograph of indoor and outdoor aged PP/SBS blends. The surface of the unaged PS-0 sample was smooth, but the surface of the sample became rough or covered with pronounced stripes after blending with SBS. The SEM images of the aged samples showed that the sample was significantly affected by temperature, ultraviolet light, and environmental factors. After 9 days of aging, the PS-0 specimens formed a large amount of irregularly rough and corrosive surfaces and cracks, while only minor cracks appeared on the surface of PP/SBS blends, and there was no significant change on the surface of the sample. After 30 days, the PS-0 specimen had completely aged, but the PS-3 blend specimen still had certain toughness. The internal morphology was shown in Fig. 3 (1), which were taken after 60 and 120 days of outdoor aging. It can be seen from the images that, the surface cracks of the pure PP samples were more pronounced, and they were completely embrittled and aged. Although the PS-2 samples also began to age, $30 \%$ of the blend specimens had cracks on the surface, as shown in Fig. 3 (2), but they still remained a certain degree of toughness, which is in consistency with the mechanical properties' data. 


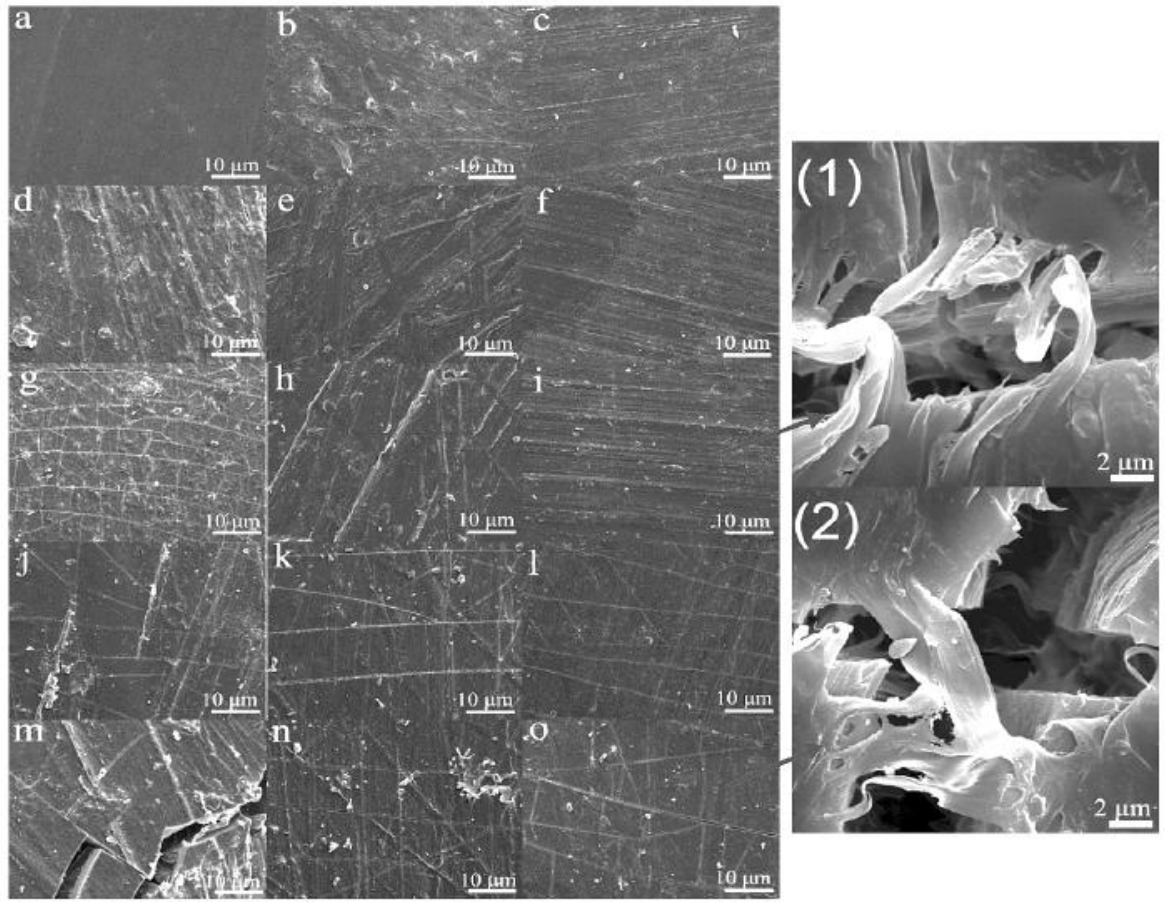

Fig. 3. SEM images of PP/SBS samples after and before aging in accelerated and natural conditions: (a, b, c) unaged PS-0, PS-2, and PS-3, respectively; (d, e, f) PS-0, PS-2, and PS-3 aged 9 days indoors, respectively; (g, h, i) PS-0, PS-2, and PS-3 aged 30 days indoors, respectively; (j, k, l) PS-0, PS-2, and PS-3 aged 60 days outdoors, respectively; (m, n, o) PS-0, PS-2, and PS-3 aged 120 days outdoors, respectively; (1) and (2): PS-3 indoor and outdoor aging 30 and 120 days, respectively (magnification 5000 times the photos).

2.4. Mechanical Properties before and after Aging Analyses of PP/SBS. Analysis of Tables 3 and 4 with the increase of SBS content, the tensile strength of the sample decreased in sequence, because the tensile strength of pure SBS is only $14.8 \mathrm{MPa}$, with the increase of SBS content in PP matrix, and The decrease of tensile strength of PP/SBS blends. The elongation at break first increased and then decreased, the elongation at break of PS-2 reached a maximum of $551 \%$. The growth rate is $41.28 \%$ higher than PS- 0 , and the PS-3 blend sample is $22.3 \%$ higher. This is because pure SBS has good toughness, its elongation at break is $696.5 \%$, and SBS added to the PP matrix, can change the crystal shape of PP, making PP spherulites are cut by the elastomer, so that PP/SBS composite material elongation at break, and then to achieve the purpose of toughening. After aging of the PP/SBS blend samples after aging in the room, the elongation at break of PS-0 specimens was reduced from 390.9 to 121.2 and $20.7 \%$ after 9 and 30 days of aging in the room, and the elongation at break was maintained at $30 \%$. And $5.2 \%$, while the ratio of the elongation at break of the PP/SBS blends with different proportions were all over $65 \%$, of which the PS-3 blend had the highest sample retention rate of $93.7 \%$; the outdoor aging was 90 and 150 days were 18.4 and $18.7 \%$, and the elongation at break was 4.7 and $4.8 \%$, indicating that the PS-0 sample had been completely corrosively aged, but the SBS-added blend sample remained as the SBS content increased. The proportions increased sequentially, and the retention ratio of the sample of more than $30 \% \mathrm{PP} / \mathrm{SBS}$ blends was still greater than $50 \%$, and the performance of the PS-3 blend sample was the best with a retention rate of $91.6 \%$; 105 days later, the samples of the blends were completely aged and corroded, and the retention rate was less than $30 \%$. 
Mechanical and Aging Properties of Polypropylene ...

\begin{tabular}{|c|c|c|c|c|c|c|c|c|}
\hline \multicolumn{9}{|l|}{$\mathrm{T} a \mathrm{~b} 1 \mathrm{e} 3$} \\
\hline \multirow{2}{*}{$\begin{array}{c}\text { SBS } \\
\text { content }(\%)\end{array}$} & \multirow{2}{*}{$\begin{array}{c}\text { Mechanical } \\
\text { properties }\end{array}$} & \multicolumn{7}{|c|}{ Aging time (days) } \\
\hline & & 0 & 3 & 6 & 9 & 15 & 20 & 30 \\
\hline \multirow[t]{2}{*}{0} & $\sigma, \mathrm{MPa}$ & 40.5 & 42.4 & 41.0 & 36.6 & 25.8 & 21.3 & 18.8 \\
\hline & $\varepsilon, \%$ & 391 & 175.9 & 140.9 & 121.3 & 29.14 & 20.7 & 20.7 \\
\hline \multirow[t]{2}{*}{10} & $\sigma, \mathrm{MPa}$ & 37.1 & 39.05 & 37.5 & 35.8 & 34.6 & 32.5 & 29.7 \\
\hline & $\varepsilon, \%$ & 474.3 & 367.2 & 234.3 & 152.2 & 34.5 & 25.1 & 24.5 \\
\hline \multirow[t]{2}{*}{20} & $\sigma, \mathrm{MPa}$ & 32.8 & 33.3 & 32.6 & 30.3 & 31.9 & 28.9 & 27.3 \\
\hline & $\varepsilon, \%$ & 551.8 & 483.1 & 421.3 & 407.6 & 246.6 & 196.6 & 124.15 \\
\hline \multirow[t]{2}{*}{30} & $\sigma, \mathrm{MPa}$ & 29.4 & 30.5 & 29.5 & 28.7 & 30.9 & 28.2 & 26.4 \\
\hline & $\varepsilon, \%$ & 477.5 & 447.6 & 406.86 & 390.1 & 322.7 & 305.5 & 282.6 \\
\hline \multirow[t]{2}{*}{40} & $\sigma, \mathrm{MPa}$ & 27.1 & 28.6 & 27.5 & 26.3 & 24.5 & 23.7 & 22.9 \\
\hline & $\varepsilon, \%$ & 438.9 & 400.6 & 362.5 & 333.6 & 292.3 & 242.3 & 219.2 \\
\hline \multirow[t]{2}{*}{50} & $\sigma, \mathrm{MPa}$ & 27.6 & 27.8 & 27.1 & 25.3 & 24.3 & 22.3 & 20.5 \\
\hline & $\varepsilon, \%$ & 407.9 & 365.3 & 316.8 & 293.9 & 259.5 & 224.8 & 204.5 \\
\hline
\end{tabular}

$\mathrm{T}$ a b 1 e 4

Mechanical Properties Test Data of PP/SBS Samples after Outdoor Exposure

\begin{tabular}{|c|c|c|c|c|c|c|c|c|c|c|c||}
\hline \multirow{2}{*}{$\begin{array}{c}\text { SBS } \\
\text { content (\%) }\end{array}$} & \multirow{2}{*}{$\begin{array}{c}\text { Mechanical } \\
\text { properties }\end{array}$} & \multicolumn{10}{|c|}{ Aging time (days) } \\
\cline { 3 - 13 } & 0 & 15 & 30 & 45 & 60 & 75 & 90 & 105 & 120 & 135 \\
\hline \multirow{2}{*}{0} & $\sigma, \mathrm{MPa}$ & 40.5 & 1.56 & 40.81 & 39.52 & 22.85 & 23.51 & 21.88 & 21.28 & 19.53 & 16.3 \\
\cline { 2 - 13 } & $\varepsilon, \%$ & 390.9 & 180.3 & 109.2 & 21.4 & 18.4 & 18.4 & 18.4 & 17.8 & 17.1 & 16.3 \\
\hline \multirow{2}{*}{10} & $\sigma, \mathrm{MPa}$ & 37.1 & 37.6 & 37.61 & 35.69 & 35.56 & 33.32 & 32.93 & 34.03 & 33.36 & 32.33 \\
\cline { 2 - 13 } & $\varepsilon, \%$ & 467.2 & 457.1 & 434.9 & 58.3 & 42.7 & 34.4 & 22.1 & 18.5 & 18.2 & 18.1 \\
\hline \multirow{2}{*}{20} & $\sigma, \mathrm{MPa}$ & 32.81 & 32.69 & 32.47 & 31.86 & 32.13 & 30.59 & 30.83 & 32.6 & 32.15 & 31.22 \\
\cline { 2 - 13 } & $\varepsilon, \%$ & 551.8 & 493.6 & 488.1 & 351.9 & 298.2 & 237.5 & 62.6 & 36.9 & 31.1 & 24.6 \\
\hline \multirow{2}{*}{30} & $\sigma, \mathrm{MPa}$ & 29.44 & 29.09 & 8.79 & 28.17 & 28.25 & 26.65 & 27.97 & 29.56 & 29.23 & 28.45 \\
\cline { 2 - 12 } & $\varepsilon, \%$ & 477.5 & 460.7 & 447.5 & 444.6 & 441.6 & 437.2 & 403.9 & 146.8 & 117.9 & 96.5 \\
\hline \multirow{2}{*}{40} & $\sigma, \mathrm{MPa}$ & 27.16 & 28.64 & 26.92 & 25.86 & 24.98 & 24.18 & 24.53 & 26.5 & 26.03 & 25.91 \\
\cline { 2 - 12 } & $\varepsilon, \%$ & 438.9 & 413.4 & 372.5 & 353.6 & 342.3 & 339.9 & 310.2 & 79.6 & 75.3 & 70.5 \\
\hline \multirow{2}{*}{50} & $\sigma, \mathrm{MPa}$ & 27.6 & 25.3 & 24.83 & 23.76 & 21.63 & 20.39 & 21.76 & 22.61 & 22.8 & 22.58 \\
\cline { 2 - 11 } & $\varepsilon, \%$ & 399.6 & 300.1 & 271.9 & 234.8 & 228.9 & 209.2 & 208.4 & 112.4 & 99.4 & 96.8 \\
\hline
\end{tabular}

2.5. Viscosity Analyze of Blends before and after Aging. From Fig. 4a, it can be seen that the torque of the unaged PP/SBS specimen increases with the increase of the SBS content during the rheology for $1 \mathrm{~min}$, because the influence of the shear force is small at the beginning of the rheology, and the blend at this time The molecular weight of the sample is closest to the molecular weight of the unaged sample. The more SBS is added, the larger the molecular weight of the composite is, the greater the torque is. With the extension of the rheological time, the torque tends to decrease because of the shear force. Under the action of the material, the flow resistance of the material decreases, the fluidity 


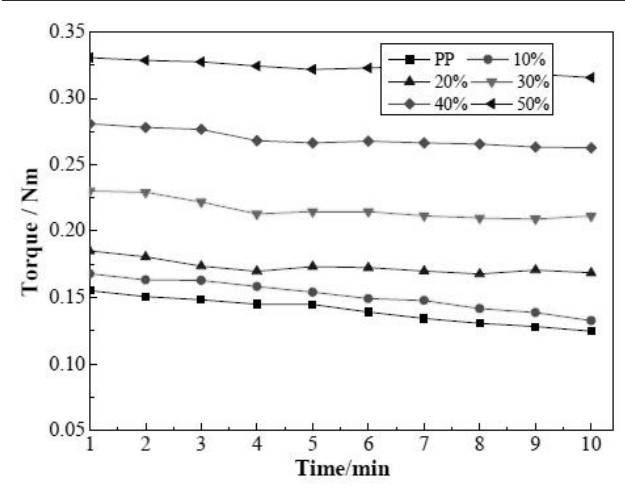

a

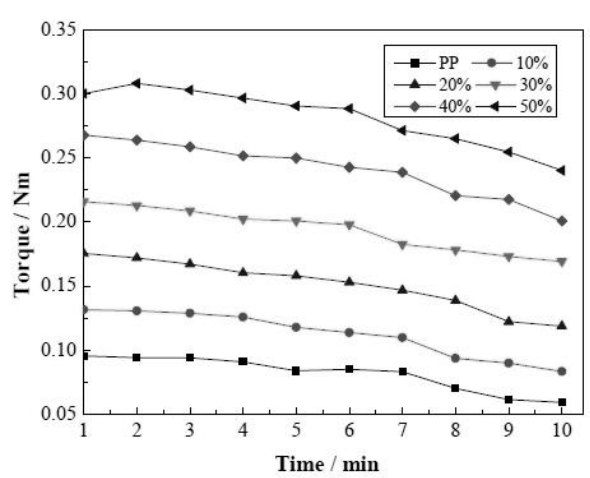

b

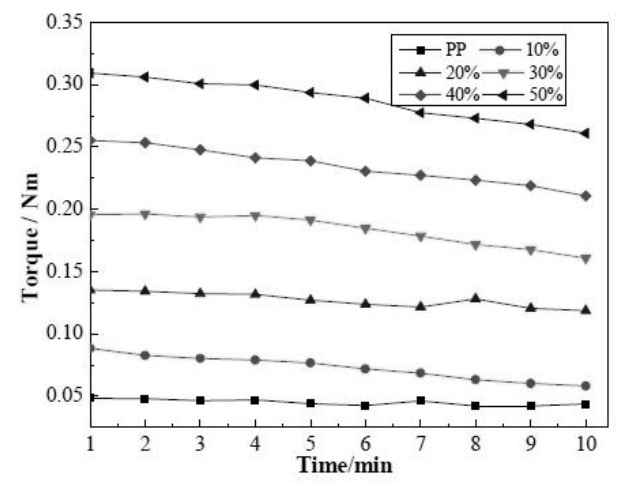

C

Fig. 4. Capillary rheology of PP/SBS samples: (a) unaged PP/SBS specimens; (b), (c) indoor aging 9 days and outdoor aging 90 days PP/SBS specimens.

increases, and the torque decreases. The initial torque values of the pure PP sample are 0.097 and $0.048 \mathrm{~N} \cdot \mathrm{m}$ of indoor aging 9 days (Fig. 4b) and outdoor aging 90 days (Fig. 4c), respectively; declined 39.4 and $70.0 \%$ comparing to the PP sample before aging. This is because the continuous thermal oxygen light attack results in the degradation and molecular chain breaking of the polypropylene, leading to the decrease of molecular weight and the subsequent change of torque. As compared to the PS-1-PS-5 sample after 90 days of outdoor aging, the initial torque value of the blends sample was maintained at 51.8, 73.1, 85.7, 91.1, and 90.6\%, respectively.

2.6. Crystal Structure Analysis of Blends before and after Aging. With the addition of the elastomer SBS, the overall intensity of the XRD peaks decreases in turn. It can be seen from Fig. 5a that the characteristic diffraction peaks of the alpha crystal phase are at $13.8,16.6$, and 18.3 , respectively, and the characteristic diffraction peak of the $\beta$ crystal phase is at 15.8. The $\beta$ crystal has a greater effect on improving the toughness of the material. The content of $\beta$ crystals can affect the toughness of the material, thus increasing the toughness of PP. At the same time, due to the existence of SBS, the crack propagation of the matrix is hindered and passivated, and the external stress that can be transmitted can be better transmitted, thus playing a role in toughening. This is proven in the test of mechanical properties. With the increase of SBS content, the diffraction peak intensity of $\beta$ crystal phase is increasing, which indicates that SBS has the effect of heterogeneous nucleation. With the prolongation of aging time, the samples of pure PP and blends obviously began to be affected by environmental factors. The longer the outdoor exposure time, the greater the degree of aging, the lower the intensity of the characteristic diffraction 


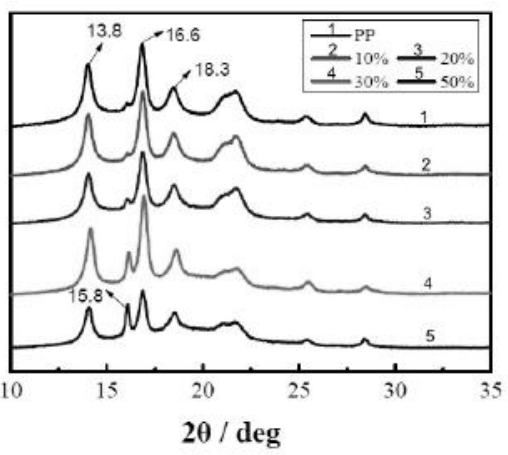

a

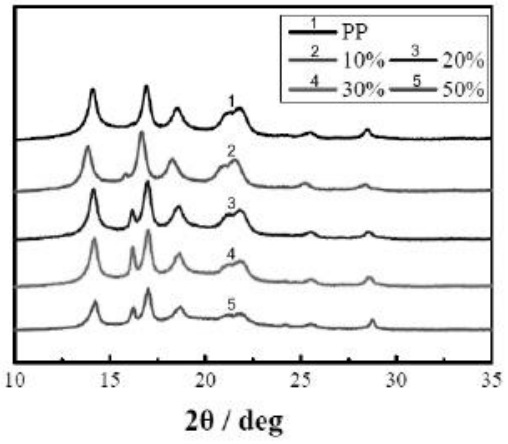

c

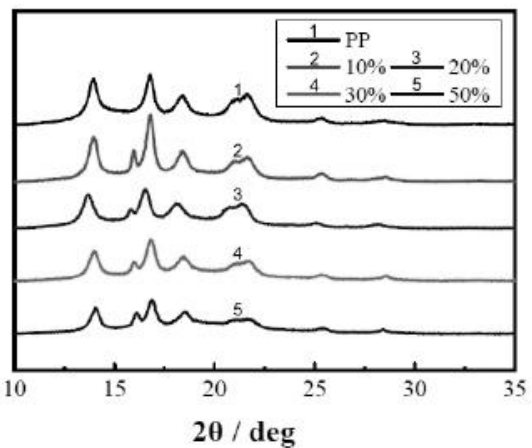

e

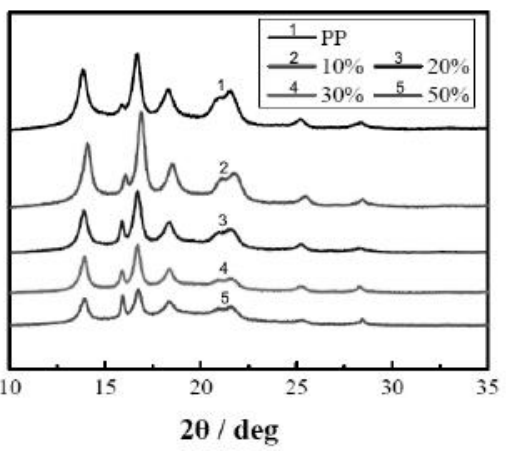

b

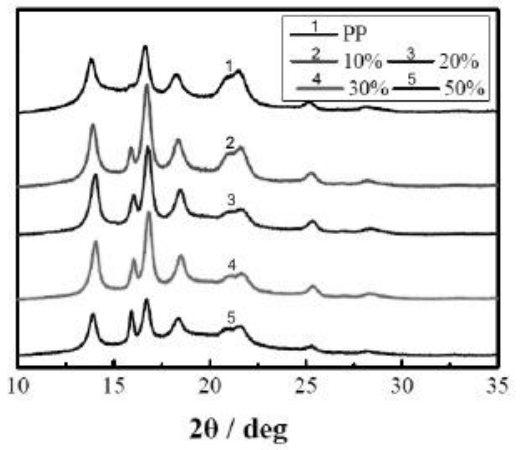

d

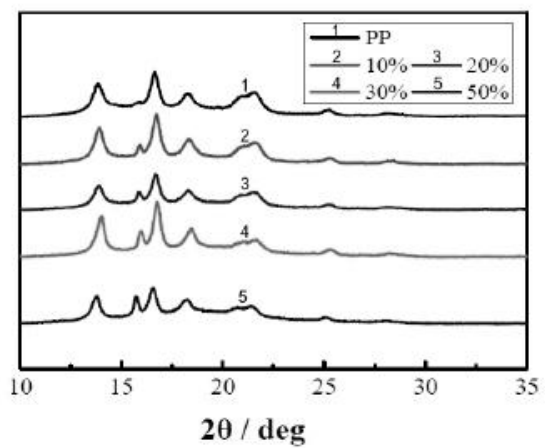

$\mathrm{f}$

Fig. 5. XRD scans for PP/SBS blend: (a) PP/SBS samples after natural aging of 0 day; (b), (c) PP/SBS samples after indoor aging of 9 and 30 days, respectively; (d), (e), (f) PP/SBS complex samples after outdoor aging of 15, 90, and 120 days, respectively.

peaks, and the lower the intensity, which is related to the indoor. The tensile strength data of the outer mechanical properties are consistent.

2.7. Surface Element Composition Analysis of Blends before and after Aging. This XPS analysis has an important role in determining the sample reaction mechanism of aging and in analyzing the indoor and outdoor aging processes that cause structural changes, which characterized the elemental composition and chemical changes in an aged sample. The XPS data shown in Figs. 5 and 6, and Table 5 show that after PP aged indoor and outdoor tests, the surface contains three functional groups, namely elemental carbon $\mathrm{C}-\mathrm{C}$, $\mathrm{C}-\mathrm{O}$, and $\mathrm{C}=\mathrm{O}$. With the increase of aging time, the $\mathrm{C}-\mathrm{C}$ on the surface of the sample gradually decreased while the $\mathrm{C}-\mathrm{O}$ and $\mathrm{C}=\mathrm{O}$ gradually increased [23]. The binding energy 
T a b 1 e 5

Changes in the Relative Molecular Mass and Distribution of Blends before and after Aging

\begin{tabular}{|c|c|c|c|c|c|c|c||}
\hline \multirow{2}{*}{$\begin{array}{c}\text { SBS content } \\
(\%)\end{array}$} & Bond & \multicolumn{3}{|c|}{ Indoor aging (days) } & \multicolumn{3}{c||}{ Outdoor time (days) } \\
\cline { 3 - 8 } & & 0 & 9 & 30 & 15 & 90 & 150 \\
\hline 0 & $\mathrm{C}-\mathrm{C}(\%)$ & 96.94 & 94.59 & 89.42 & 87.14 & 87.02 & 85.96 \\
& $\mathrm{C}-\mathrm{O}(\%)$ & 3.06 & 3.30 & 5.50 & 7.62 & 8.43 & 9.14 \\
& $\mathrm{C}=\mathrm{O}(\%)$ & 0 & 2.11 & 5.08 & 5.24 & 4.55 & 4.90 \\
\hline 30 & $\mathrm{C}-\mathrm{C}(\%)$ & 95.27 & 92 & 86.09 & 87.89 & 80.9 & 80.9 \\
& $\mathrm{C}-\mathrm{O}(\%)$ & 4.73 & 4.61 & 8.33 & 7.46 & 10.58 & 10.58 \\
& $\mathrm{C}=\mathrm{O}(\%)$ & 0 & 3.39 & 5.58 & 4.47 & 8.52 & 8.52 \\
\hline
\end{tabular}

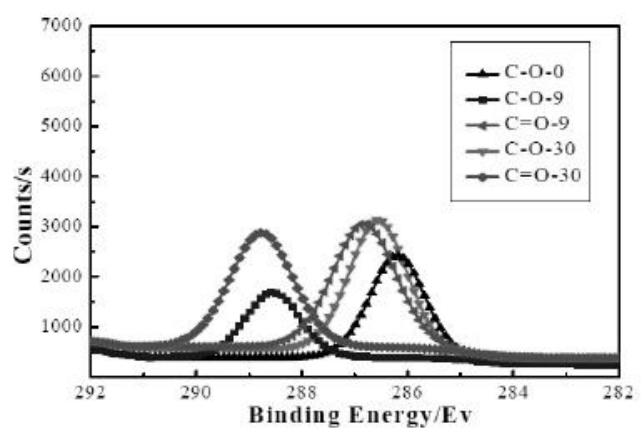

a

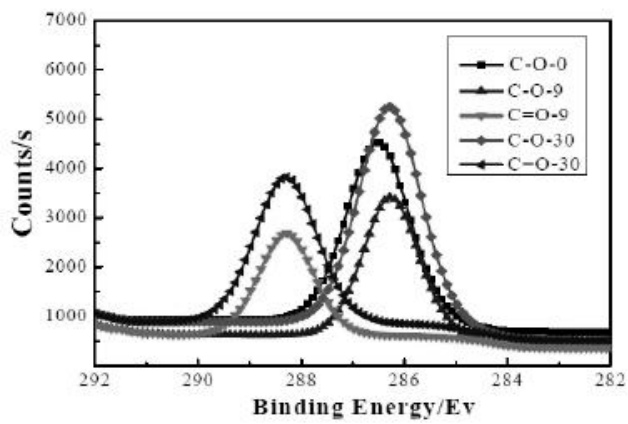

$\mathrm{c}$

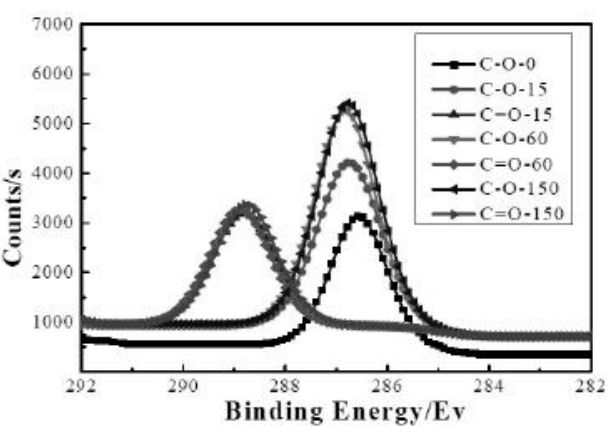

b

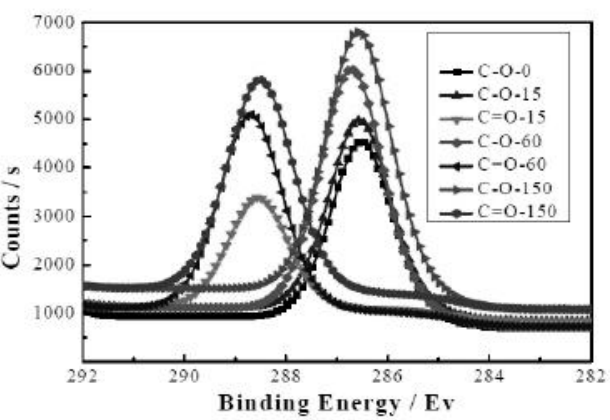

d

Fig. 6. Changes in the relative molecular mass and distribution of PS-0 and PS-3 after indoor and outdoor aging: (a), (b) PS-0 after indoor and outdoor aging; (c), (d) PS-3 after indoor and outdoor aging.

ranged from 285.2 to $288.4 \mathrm{eV}$. Compared with pure $\mathrm{PP}$, the $\mathrm{C}=\mathrm{O}$ functional groups of PS-3 composites increased by $3.39,5.58,8.52$, and $11 \%$ in indoor aging at 9 and 30 days and outdoor aging at 90 and 150 days, respectively. They were $2.11,5.08,8.43$, and $9.14 \%$, respectively. This is because the PP structure contains a tertiary hydrogen that can easily generate hydrogen peroxide, thereby accelerating the formation of hydrogen peroxide in the main chain and the $\mathrm{C}=\mathrm{C}$ chemical covalent (pi) bond in the $\mathrm{PB}$ segment is first excited by heat or ultraviolet light. Into polymer radicals, and the decomposition of unstable peroxide intermediates produces carbonyl compounds, epoxy ethers are composed of polymer radicals and molecular oxygen, PP structure contains a tertiary hydrogen, hydrogen peroxide can be easily generated. This accelerates the formation of hydrogen peroxide in the main chain. 
Conclusions. This study proved that PP/SBS blends have a good low-temperature performance. While SBS is mixed into PP with a certain proportion, the mechanical properties of the material increase first and then decrease with the increase of SBS content. Among these samples, the mechanical properties of PS-2, which is the $20 \mathrm{wt} . \%$ containing PP sample, are found to be the best. After low temperature freezing test, is found. The addition of SBS is found to have excellent low-temperature toughness, which can effectively improve the short-term brittleness of PP, thus providing a certain support for broadening the scope of the application of PP products.

The accelerated aging test revealed that, at a temperature difference of $55^{\circ} \mathrm{C}$, with the increase of aging time, the performance of the blend sample is decreased. A variety of tests showed that, the long-term anti-aging effect is the best when the SBS added amount is 30 wt.\%, and the anti-aging effect enhances with the increase of the SBS content.

After being exposed to sun in the Turpan area for 5 months, under the conditions of high outdoor temperature, high UV and other comprehensive conditions, the pure PP sample started to lose its value in use after being degraded in the outdoors for 15 days, and lost its use value completely in 45 days. The addition of SBS obviously slows down the aging of the sample. The blend sample with $30 \mathrm{wt} . \%$ of SBS completely lost its use value in 105 days outdoors, which is $57.14 \%$ higher than that of pure PP, indicating the long-lasting anti-aging effect of the PP/SBS blends.

Acknowledgements. The authors wish to acknowledgement the financial support of the National Natural Science Foundation of China (Nos. 21474082 and 21364014).

1. F. A. Ghasemi, S. Daneshpayeh, I. Ghasemi, and M. Ayaz, "An investigation on the Young's modulus and impact strength of nanocomposites based on polypropylene/ linear low-density polyethylene/titan dioxide $\left(\mathrm{PP} / \mathrm{LLDPE} / \mathrm{TiO}_{2}\right)$ using response surface methodology," Polym. Bull., 73, No. 6, 1741-1760 (2016).

2. M. Khodabandelou and M. K. R. Aghjeh, "Impact behavior of CNT-filled PP/EPDM blends: effect of dynamic vulcanization and PP-g-MA compatibilizer," Polym. Bull., 73, No. 6, 1607-1626 (2016).

3. X. J. Lai, S. Tang, H. Q. Li, and X. R. Zeng, "Flame-retardant mechanism of a novel polymeric intumescent flame retardant containing caged bicyclic phosphate for polypropylene," Polym. Degrad. Stabil., 113, 22-31 (2015).

4. P. A. Zapata, F. M. Rabaliati, I. Lieberwirth, et al., "Study of the photodegradation of nanocomposites containing $\mathrm{TiO}_{2}$ nanoparticles dispersed in polyethylene and in poly(ethylene-co-octadecene)," Polym. Degrad. Stabil., 109, 106-114 (2014).

5. Y. M. Li, G. X. Wei, and H. J. Sue, "Morphology and toughening mechanisms in clay-modified styrene-butadiene-styrene rubber-toughened polypropylene," J. Mater. Sci., 37, No. 12, 2447-2459 (2002).

6. P. Raghu, C. K. Nere, and R. N. Jagtap, "Effect of styrene-isoprene-styrene, styrene-butadiene-styrene, and styrene-butadiene-rubber on the mechanical, thermal, rheological, and morphological properties of polypropylene/polystyrene blends," $J$. Appl. Polym. Sci., 88, No. 2, 266-277 (2003).

7. Y. Li, J. T. Huang, X. Lu, et al., "Influences of dicumyl peroxide on morphology and mechanical properties of polypropylene/poly(styrene- $b$-butadiene- $b$-styrene) blends via vane-extruder," J. Appl. Polym. Sci., 132, No. 9 (2015), DOI: 10.1002/app.41543.

8. S. M. Al-Salem, B. K. Sharma, A. R. Khan, et al., "Thermal degradation kinetics of virgin polypropylene (PP) and PP with starch blends exposed to natural weathering," Ind. Eng. Chem. Res., 56, No. 18, 5210-5220 (2017).

9. J. González, C. Albano, M. V. Candal, et al., "Characterization of blends of PP and SBS vulcanized with gamma irradiation," Nucl. Instrum. Meth. B, 236, Nos. 1-4, 354-358 (2005). 
10. M. Saroop and G. N. Mathur, "Studies on dynamically vulcanized polypropylene (PP)/butadiene styrene block copolymer (SBS) blends: Crystallization and thermal behavior," J. Appl. Polym. Sci., 71, No. 1, 151-161 (1999).

11. P. Lin, W. D. Huang, N. P. Tang, and F. P. Xiao, "Performance characteristics of terminal blend rubberized asphalt with SBS and polyphosphoric acid," Constr. Build. Mater., 141, 171-182 (2017).

12. N. Nciri, N. Kim, and N. Cho, "New insights into the effects of styrene-butadienestyrene polymer modifier on the structure, properties, and performance of asphalt binder: The case of AP-5 asphalt and solvent deasphalting pitch," Mater. Chem. Phys., 193, 477-495 (2017).

13. A. K. Swamy, U. D. Rongali, and P. K. Jain, "Effect of HDPEH polymer on viscoelastic properties of SBS modified asphalt," Constr. Build. Mater., 136, 230-236 (2017).

14. C. Xin, Q. Lu, C. Ai, et al., "Optimization of hard modified asphalt formula for gussasphalt based on uniform experimental design," Constr. Build. Mater., 136, 556564 (2017).

15. M. Wang and L. P. Liu, "Investigation of microscale aging behavior of asphalt binders using atomic force microscopy," Constr. Build. Mater., 135, 411-419 (2017).

16. L. Sun, X. T. Xin, and J. L. Ren, "Asphalt modification using nano-materials and polymers composite considering high and low temperature performance," Constr. Build. Mater., 133, 358-366 (2017).

17. P. Wang, Z. J. Dong, Y. Q. Tan, and Z. Y. Liu, "Effect of multi-walled carbon nanotubes on the performance of styrene-butadiene-styrene copolymer modified asphalt," Mater. Struct., 50, 17 (2017), DOI: 10.1617/s11527-016-0890-9.

18. W. Yin, F. Ye, and H. Lu, "Establishment and experimental verification of stability evaluation model for SBS modified asphalt: Based on quantitative analysis of microstructure," Constr. Build. Mater., 131, 291-302 (2017).

19. Y. Y. Wang, L. Sun, and J. Zhou, "Pavement performance evaluation of recycled styrene-butadiene-styrene-modified asphalt mixture," Int. J. Pavement Eng., 18, No. 5, 404-413 (2017).

20. J. Y. Pang, S. J. Du, R. T. Chang, and Q. Pei, "The properties of SBS-modified asphalt binder in the presence of dithiodimorpholine and tetraethyl thiuram disulphide," Road Mater. Pavement, 17, No. 2, 466-476 (2016).

21. J. Tocháček and Z. Vrátničková, "Polymer life-time prediction: The role of temperature in UV accelerated ageing of polypropylene and its copolymers," Polym. Test., 36, 82-87 (2014).

22. D. D. Song, J. Gao, X. G. Li, and L. Lu, "Evaluation of aging behavior of polypropylene in natural environment by principal component analysis," Polym. Test., 33, 131-137 (2014).

23. X. Xu, J. Y. Yu, C. L. Zhang, et al., "Investigation of aging behavior and thermal stability of styrene-butadiene-styrene tri-block copolymer in blends," Polymer (Korea), 40, No. 6, 947-953 (2016). 